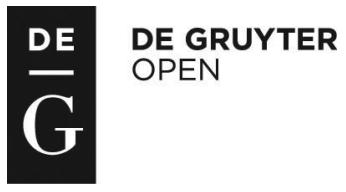

\title{
PERFORMANCE AND PHOSPHORUS UTILIZATION OF BROILER CHICKENS FED LOW PHYTATE BARLEY AND PEA BASED DIETS WITH GRADED LEVELS OF INORGANIC PHOSPHORUS
}

\author{
Roseline Kafedha Kahindi' ${ }^{1}$, Philip A. Thacker ${ }^{2}$, Sang In Lee ${ }^{3}$, In Ho Kim³ ${ }^{3}$, Charles Martin Nyachoti ${ }^{1 \star}$ \\ ${ }^{1}$ Department of Animal Science, University of Manitoba, Winnipeg, MB, R3T 2N2, Canada \\ ${ }^{2}$ Department of Animal and Poultry Science, University of Saskatchewan, Saskatoon, SK, \\ 51 Campus Drive, S7N 5A8, Canada \\ ${ }^{3}$ Department of Animal Resource and Science, Dankook University, Cheonan, Choongnam, Korea \\ •Corresponding author: martin_nyachoti@umanitoba.ca
}

\begin{abstract}
The effects of feeding diets based on soybean meal, low phytate hulless barley (Lphybarley) and low phytate pea (Lphypea) with inorganic phosphorus (iP) reduced by 50 or $100 \%$ to broiler chickens on performance, $P$ digestibility and bone characteristics were investigated. Two hundred and ten day-old (Ross 308 strain) broiler chicks ( 5 birds per cage; 6 cages per diet) were randomly allocated to 7 dietary treatments for a 21-day study. Diets were formulated based on soybean meal-normal phytate hulless barley (SBM-normbarley) with added inorganic P (iP) to meet NRC (1994) P requirements (SBM-normbarley100) or with 50\% less iP (SBM-normbarley50), soybean meal-Lphybarley-Lphypea with added iP (Lphybarley-Lphypea100) or iP reduced by $\mathbf{5 0 \%}$ (Lphybarley-Lphypea50) or 100\% (Lphybarley-Lphypea0), and soybean meal-normbarleynormal phytate pea (normpea) with added iP (normbarley-normpea100) or iP reduced by $50 \%$ (normbarley-normpea50). Birds fed the Lphybarley-Lphypea0 diet had the lowest $(\mathbf{P}<0.001)$ ADG compared with those fed the other diets. Reducing iP by $50 \%$ led to a reduction $(\mathrm{P}<0.05)$ in ADG for birds fed the SBM-normbarley- and normbarley-normpea-based diets but not in the Lphybarley-Lphypea-based diet. Reducing iP by $50 \%$ led to a reduction $(\mathrm{P}<0.05)$ in ADFI in birds fed the SBM-normbarley-based diet and normbarley-normpea-based diet compared with those fed adequate iP. Feed conversion ratio was not affected by diet throughout the experimental period $(P>0.10)$. Reducing iP content reduced $P$ retention in the SBM-normbarley-based diet but not in the normbarley-normpea-based diet but tibia ash and length were reduced in birds fed both diets $(\mathrm{P}<0.05)$. Reducing dietary iP content linearly increased $(\mathrm{P}<0.05) \mathrm{P}$ retention and linearly decreased $(\mathrm{P}<0.05)$ tibia ash and length in the Lphypea-Lphybarley-based diets. In conclusion, feeding a low phytate hulless barley-low phytate pea based diet with iP reduced by $50 \%$ supported similar performance as control and increased $P$ retention, suggesting that utilizing a combination of low phytate ingredients can reduce the need for supplemental iP with significant cost and environmental implication.
\end{abstract}

Key words: broilers, bone mineralization, low phytate pea, phosphorus, performance 
Majority of phosphorus (P) in plant based feedstuffs is bound as phytate, which is poorly digested by non-ruminant animals (Ravindran et al., 1995; Woyengo and Nyachoti, 2013) thus contributing to the emission of excess P into the environment. To enhance utilization of the $P$ present in these ingredients, various strategies such as phytase supplementation and the use of low-phytate feedstuffs have been developed. To this end, various studies have shown that $\mathrm{P}$ in low phytate feedstuffs such as corn, soybean meal, barley, and pea is more digestible and better utilized by poultry compared with conventional varieties (Dilger and Adeola, 2006; Leytem et al., 2007; Thacker et al., 2013; Kahindi et al. 2015).

In addition to its potential to cause environmental pollution, $\mathrm{P}$ is a costly nutrient in poultry diets and therefore optimizing its utilization is critical to controlling the cost of production. Therefore, in the present study it was hypothesized that formulating broiler chicken diets using a combination of low phytate hulless barley and low phytate pea as the main ingredients can partially or completely eliminate the need for inorganic P supplementation while supporting adequate growth performance. Thus, the objectives of the present study were to determine the effects of feeding diets containing low phytate barley and pea compared with normal phytate cultivars and the effects of reducing inorganic $\mathrm{P}$ by 50 or $100 \%$ on performance, $\mathrm{P}$ digestibility and bone characteristics of broiler chickens.

\section{Material and methods}

\section{General}

Birds were housed and managed according to the Canadian Council on Animal Care Guidelines (2009). The experimental protocol (F11-003/1/2/3) was reviewed and approved by the University of Manitoba Animal Care Committee.

\section{Birds and housing}

Two hundred and ten, day-old (Ross 308 strain) broiler chickens were obtained from a commercial hatchery (Carlton Hatchery, Grunthal, Manitoba, Canada). Chicks were individually weighed upon arrival and divided into 30 groups each with 7 birds balanced for BW. They were then allocated in a completely randomised design to 1 of 7 dietary treatments to yield 6 replicate cages each with 5 birds. The brooder and room temperature were set at $32^{\circ} \mathrm{C}$ during the first week. During week 2 and 3 , heat supply in the brooder was turned off and room temperature was dropped by $1.5^{\circ} \mathrm{C}$ in each week. Light was provided for $24 \mathrm{~h}$ daily throughout the 21-day experimental period.

\section{Dietary treatments}

The low phytate barley (Lphybarley; cultivar CDC Lophy-1), low phytate pea (Lphypea; cultivar 1-2346-144), normal phytate pea (normpea; cultivar CDC Bronco), and normal phytate hulless barley (normbarley) used in the current study were developed at the University of Saskatchewan's Crop Development Center (Saskatoon, SK, Canada). Soybean meal was used as a protein supplement in all diets (Ta- 
ble 1). The diets contained sufficient nutrients for a broiler starter diet as recommended by NRC (1994) with the exception of P, where some diets had inorganic P added to meet available $P$ requirements for broiler chickens and in other diets the amount of inorganic $\mathrm{P}$ added was reduced by 50 or $100 \%$ (Table 2). All diets contained titanium dioxide $(3 \mathrm{~g} / \mathrm{kg})$ as an indigestible marker and there was no phytase addition. Dietary treatments were: 1) soybean meal-normal phytate hulless barley supplemented with sufficient inorganic P (100\% inclusion) to meet NRC (1994) P requirements (SBM-normbarley100), 2) soybean meal-normal phytate hulless barley with the amount of inorganic P reduced by $50 \%$ (SBM-normbarley50), 3) soybean meal-low phytate hulless barley-low phytate pea with 100\% inclusion of inorganic P to meet P requirements (Lphybarley-Lphypea100), 4) soybean meal-low phytate hulless barley-low phytate pea with the amount of inorganic P reduced by 50\% (Lphybarley-Lphypea50), 5) soybean meallow phytate hulless barley-low phytate pea with $0 \%$ inclusion of inorganic P (Lphybarley-Lphypea0), 6) soybean meal-normal phytate hulless barley-normal phytate pea with $100 \%$ inclusion of inorganic $\mathrm{P}$ to meet P requirements (normbarley-normpea100), 7) soybean meal-normal phytate hulless barley-normal phytate pea with inorganic $\mathrm{P}$ reduced by $50 \%$ (normbarley-normpea50). Feed and water were offered for $a d-$ libitum intake throughout the 21-day study.

\section{Data and sample collection}

Feed consumption and body weights of birds per cage were determined weekly and these measurements used to calculate average daily gain (ADG), average daily feed intake (ADFI), and feed conversion ratio (FCR). On days 19 and 20, excreta samples were collected from each cage and stored at $-20^{\circ} \mathrm{C}$ until required for analysis. On day 21, all birds were killed by carbon dioxide asphyxiation and the left tibias from 2 birds of median weight per cage obtained for bone length and ash determination.

\section{Chemical analyses}

Excreta samples were freeze-dried and along with ingredients and diet samples ground to pass through a $1 \mathrm{~mm}$ sieve before chemical analyses. Ingredients (i.e. soybean meal, barley, and pea), diets, and excreta samples were analyzed for DM, P and $\mathrm{N}$ contents. Ingredients were further analyzed for phytate content as were diets and excreta sample for titanium content. Tibia length was measured and tibia ash determined as described by Woyengo et al. (2010).

Dry matter content was determined according to AOAC (1990; Code No. 925.09) whereas nitrogen content was determined using a combustion analyzer (Model CNC2000; Leco Corporation, St. Joseph, MI). Calcium and P were analyzed according to AOAC (1990; Code No. 990.08) and read on a Varian Inductively Coupled Plasma Mass Spectrometer (Varian Inc., Palo Alto, CA). Phytate content in soybean meal, pea and barley was determined by the method of Haug and Lantzsch (1983). Titanium was determined according to the method of Lomer et al. (2000) with some modifications in the duration of digestion time and temperature settings. Briefly, samples were ashed at $550^{\circ} \mathrm{C}$ for $12 \mathrm{~h}$ followed by digestion in sulfuric acid for $2 \mathrm{~h}$ at $350^{\circ} \mathrm{C}$ then diluted with deionized water before quantification using an Inductively Coupled Plasma Mass Spectrometry (Varian Inc., Palo Alto, CA). 
Table 1. Analyzed chemical composition of soybean meal (SBM) and low and normal phytate pea and barley (in \%)

\begin{tabular}{l|r|r|r|r|r}
\hline & \multirow{2}{*}{ SBM } & \multicolumn{2}{|c|}{ Barley } & \multicolumn{2}{c}{ Peas } \\
\cline { 3 - 6 } & & normal & low phytate & normal & low phytate \\
\hline Dry matter & 89.00 & 90.00 & 90.00 & 89.00 & 89.00 \\
Crude protein & 46.20 & 12.40 & 12.00 & 22.20 & 22.70 \\
Calcium & 0.28 & 0.03 & 0.03 & 0.07 & 0.05 \\
Total phosphorus & 0.69 & 0.34 & 0.35 & 0.44 & 0.44 \\
Non-phytate P & 0.32 & 0.17 & 0.31 & 0.24 & 0.37 \\
Methionine & 0.65 & 0.20 & 0.20 & 0.20 & 0.20 \\
Cysteine & 0.70 & 0.21 & 0.21 & 0.30 & 0.28 \\
Lysine & 2.95 & 0.45 & 0.45 & 1.45 & 1.47 \\
Threonine & 1.51 & 0.37 & 0.41 & 0.84 & 0.84 \\
Tryptophan & 0.64 & 0.13 & 0.13 & 0.19 & 0.19 \\
\hline
\end{tabular}

Table 2. Ingredient composition (\%) of experimental diets ${ }^{1}$

\begin{tabular}{l|rr|r|r|r|rr}
\hline & \multicolumn{2}{|c|}{ SBM-normbarley } & \multicolumn{2}{c|}{ SBM-Lphybarley-Lphypea } & \multicolumn{2}{c}{$\begin{array}{c}\text { SBM-normbarley- } \\
\text {-normpea }\end{array}$} \\
\cline { 2 - 8 } & $100 \%$ iP & \multicolumn{1}{c}{$50 \%$ iP } & $100 \%$ iP & $50 \%$ iP & $0 \%$ iP & $100 \%$ iP & $50 \%$ iP \\
\hline Soybean meal & 33.00 & 33.00 & 22.00 & 22.00 & 22.00 & 22.00 & 22.00 \\
Barley, low phytate & 0.00 & 0.00 & 23.95 & 23.95 & 23.95 & 0.00 & 0.00 \\
Barley, normal phytate & 42.50 & 42.50 & 0.00 & 0.00 & 0.00 & 23.95 & 23.95 \\
Peas, low phytate & 0.00 & 0.00 & 29.50 & 29.50 & 29.50 & 0.00 & 0.00 \\
Peas, normal phytate & 0.00 & 0.00 & 0.00 & 0.00 & 0.00 & 29.50 & 29.50 \\
Sucrose & 10.00 & 10.00 & 10.00 & 10.00 & 10.00 & 10.00 & 10.00 \\
Dextrose & 1.74 & 2.14 & 2.00 & 2.29 & 2.59 & 1.74 & 2.14 \\
Canola oil & 7.50 & 7.50 & 7.46 & 7.46 & 7.46 & 7.46 & 7.46 \\
Limestone & 1.70 & 2.04 & 1.93 & 2.17 & 2.40 & 1.75 & 2.10 \\
Monocalcium phosphate & 1.48 & 0.74 & 1.06 & 0.53 & 0.00 & 1.50 & 0.75 \\
DL-Methionine & 0.33 & 0.33 & 0.37 & 0.37 & 0.37 & 0.37 & 0.37 \\
L-Threonine & 0.15 & 0.15 & 0.13 & 0.13 & 0.13 & 0.13 & 0.13 \\
Sodium chloride & 0.30 & 0.30 & 0.30 & 0.30 & 0.30 & 0.30 & 0.30 \\
Vitamin-mineral premix ${ }^{2}$ & 1.00 & 1.00 & 1.00 & 1.00 & 1.00 & 1.00 & 1.00 \\
Titanium dioxide & 0.30 & 0.30 & 0.30 & 0.30 & 0.30 & 0.30 & 0.30 \\
Total & 100.00 & 100.00 & 100.00 & 100.00 & 100.00 & 100.00 & 100.00 \\
\hline
\end{tabular}

${ }^{1} \mathrm{SBM}=$ soybean meal; normbarley = normal phytate hulless barley; Lphybarley = low-phytate barley; Lphypea $=$ low phytate pea.

${ }^{2}$ Supplied per kg of diet: $8550 \mathrm{IU}$ - vitamin A, $300 \mathrm{IU}$ - vitamin $\mathrm{D}_{3}, 30 \mathrm{IU}$ - vitamin E, $16 \mu \mathrm{g}$ - vitamin $\mathrm{B}_{12}, 2 \mathrm{mg}$ - vitamin K, $55 \mathrm{mg}$ - niacin, $1300 \mathrm{mg}$ - choline chloride, $6 \mathrm{mg}$ - riboflavin, $1 \mathrm{mg}$ - folic acid, $16 \mu \mathrm{g}$

- biotin, $3 \mathrm{mg}$ - thiamin, $1.25 \mathrm{mg}$ - calcium iodate, $120 \mathrm{mg}$ - manganese, $80 \mathrm{mg}$ - zinc, $80 \mathrm{mg}$ - iron, $10 \mathrm{mg}$

- copper, $0.3 \mathrm{mg}$ - selenium.

\section{Calculations and statistical analyses}

Phosphorus retention of nutrients was calculated as described by Woyengo et al. (2010). Tibia ash was calculated as follows: Tibia ash (\%) $=100 *$ (weight of tibia ash/ weight of fat free tibia). Mortality was calculated as the number of birds dead per treatment divided by initial total number and the product multiplied by 100 . 
Data were subjected to analysis of variance as a completely randomized design using the Mixed Procedure of SAS (SAS Software Release 9.2, SAS Institute, Cary, NC). In addition, orthogonal contrasts were used to compare the output from diets with low phytate vs. normal phytate ingredients.

\section{Results}

The analyzed nutrient composition of the test ingredients and diets are given in Tables 1 and 3, respectively. Energy and nutrient contents were similar between the normal and low-phytate hulless barley and pea varieties. Dietary phytate P content ranged from 0.09 to $0.17 \%$, the highest value being for the normbarley-normpea- and the lowest for the Lphybarley-Lphypea-based diets.

Although most of birds in the study were healthy throughout the experiment, there were mortalities recorded for SBM-normbarley50 (6.7\%), Lphybarley-Lphypea0 (26.7\%) and normbarley-normpea50 (10\%). The birds fed the Lphybarley-Lphypea0 diet had the lowest $(\mathrm{P}<0.001)$ ADG compared with those fed the other diets. Reducing iP by $50 \%$ led to a reduction $(\mathrm{P}<0.05)$ in $\mathrm{ADG}$ for birds fed the SBM-normbarley- and normbarley-normpea-based diets but had no effect in the Lphybarley-Lphypea-based diet (Table 4). On average, birds fed diets containing sufficient amounts of iP to meet $\mathrm{P}$ requirements had higher $(\mathrm{P}<0.001)$ ADG than those fed diets with iP reduced by $50 \%$.

The birds fed the Lphybarley-Lphypea0 diet had the lowest $(\mathrm{P}<0.001)$ ADFI compared to those fed the other diets (Table 4). Reducing iP by 50\% led to a significant reduction $(\mathrm{P}<0.05)$ in ADFI in birds fed the SBM-normbarley-based diet and those fed the normbarley-normpea-based diet compared with those fed adequate iP (Table 4). On average, birds fed diets containing sufficient amounts of iP to meet $\mathrm{P}$ requirements had higher $(\mathrm{P}<0.001)$ ADFI than those fed diets with iP reduced by $50 \%$. Feed conversion ratio was not affected by diet $(\mathrm{P}>0.10$; Table 4$)$.

The DM digestibility was similar in all diets except for normbarley-normpea50 diet. The pea-based diets had higher $(\mathrm{P}<0.05)$ crude protein digestibility compared with the SBM-normbarley-based diets (Table 5). Reducing the iP content from 100 to $0 \%$ linearly increased $(\mathrm{P}<0.05)$ the apparent $\mathrm{P}$ retention but linearly decreased $(\mathrm{P}<0.05)$ tibia ash and length in birds fed the Lphypea-Lphybarley-based diets (Table 5). Hence, birds fed the diet with no added iP had the lowest tibia ash content and length. The P retention was similar in birds fed the normbarley-normpea-based diets regardless of the iP content. The P excretion was lowest for the Lphypea-Lphybarley-based diets (Table 5). However, reducing iP content decreased tibia ash and length in birds fed the normbarley-normpea-based diets. Reducing the inorganic $\mathrm{P}$ content in the SBM-normbarley-based diets decreased $(\mathrm{P}<0.05) \mathrm{P}$ retention, tibia ash and length. Also, birds fed the Lphybarley-Lphypea-based diets had significantly higher $(\mathrm{P}<0.05) \mathrm{P}$ retention than birds fed the normbarley-normpea-based diets (Table 5). 


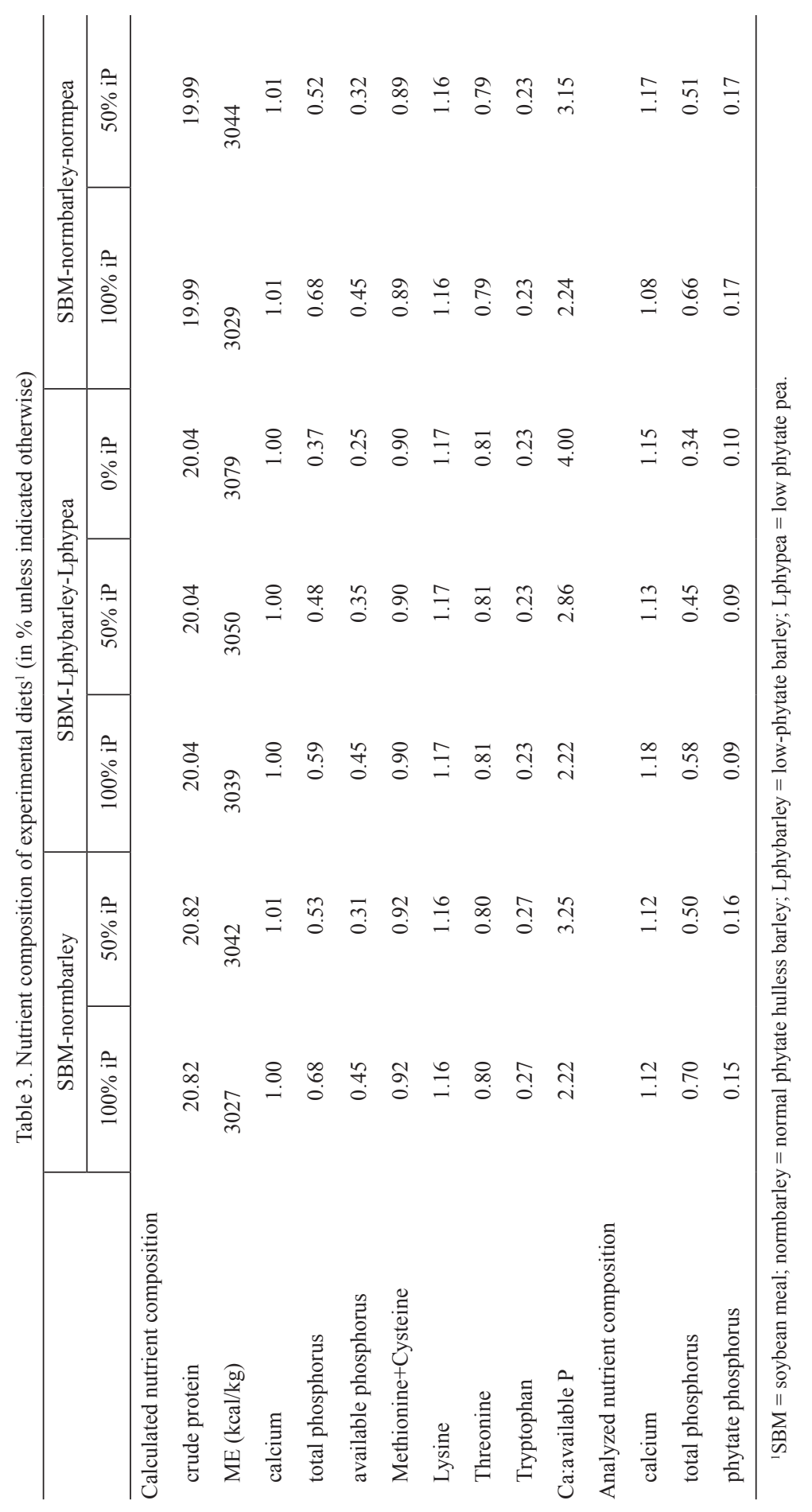




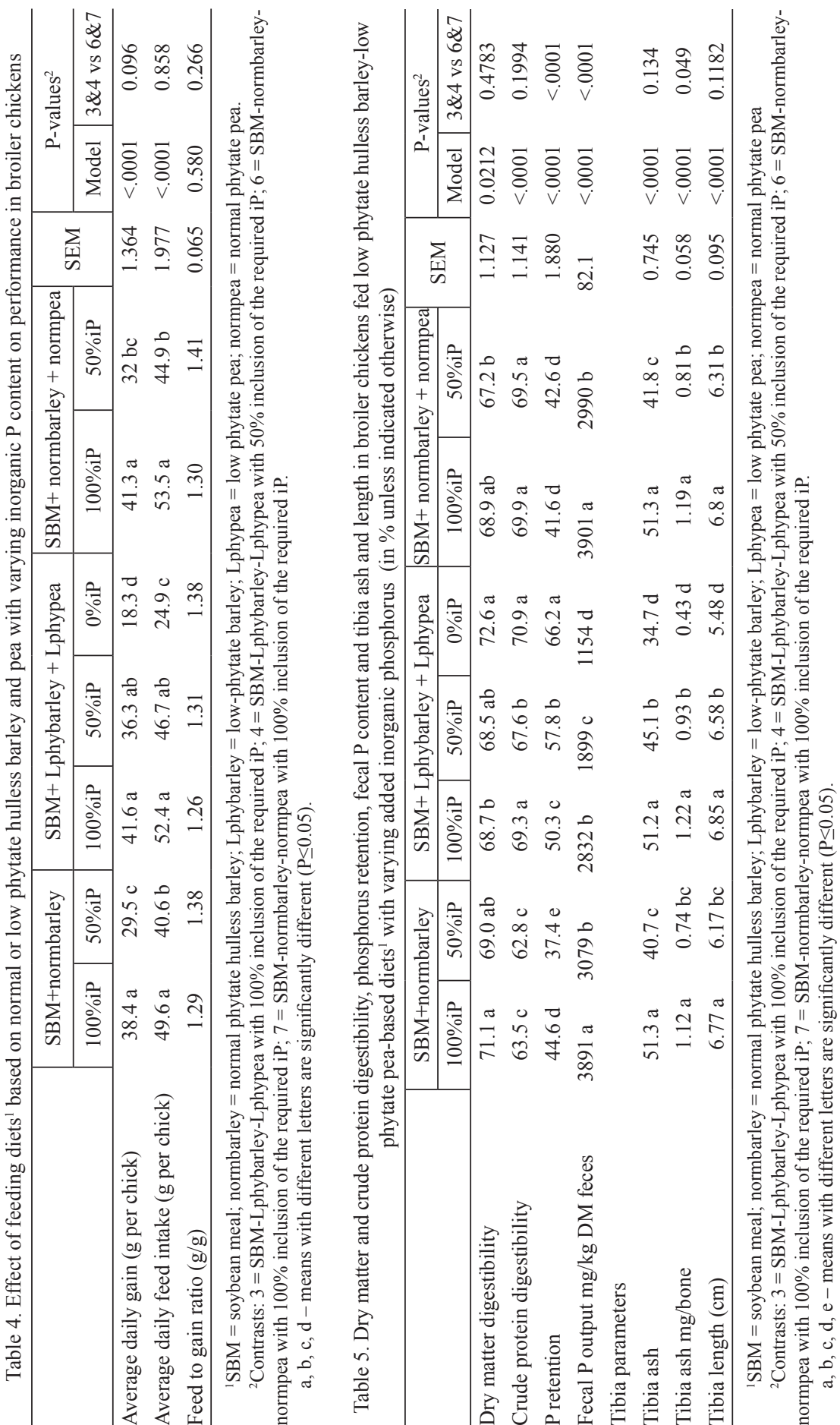




\section{Discussion}

The CP, Ca and P contents of the low phytate pea and barley varieties were similar to values reported by Thacker et al. (2013) and Kahindi et al. (2015). This is because the Lphypea and Lphybarley cultivars were the same as those used in the previously mentioned studies. The $\mathrm{CP}, \mathrm{Ca}$ and $\mathrm{P}$ content of SBM were similar to values reported by NRC (2012) and Thacker et al. (2013). The analyzed and calculated dietary P content values were similar. However, the Ca content was higher than the calculated values in all diets. The disparity between the analyzed and calculated $\mathrm{Ca}$ content in all the diets could be due to the inclusion of calcium iodate in the vitamin-mineral premix.

Unlike the SBM-normbarley- and normpea-normbarley-based diets, reducing the inorganic P content by 50\% in the Lphypea-Lphybarley based diet did not result in mortalities. Therefore, mortalities were only observable in the Lphypea-Lphybarley based diet with no supplemental inorganic $\mathrm{P}$ which had a total $\mathrm{P}$ content of $0.34 \%$. Furthermore, the broiler chickens fed the Lphypea-Lphybarley0 diet showed signs of leg weakness portrayed by rickets but there were no fractures. The leg weakness affected the birds' ability to access feed thereby contributing to the mortalities and retarded growth observed for this treatment.

Reduction in the available P content negatively affected the broiler chickens as shown by a depression in feed intake and growth. The reduction in growth of broiler chickens resulting from lower dietary P content is similar to work by Sebastian et al. (1997) and Thacker et al. (2013) and is a typical sign of P deficiency. Phosphorus plays a key role in metabolic processes such as skeleton formation, mineralization and also controls growth, energy utilization and protein synthesis by being part of nucleic acids, phospholipids as well as phosphoproteins (Berndt et al., 2007; Veum, 2010; Penido and Alon, 2012). Thus, these metabolic processes would be compromised in the case of a $\mathrm{P}$ deficiency. The drop in feed intake could also be as a result of a wide Ca:P ratio ( $>2: 1)$ in some diets. A high Ca content depresses phytate hydrolysis and $\mathrm{P}$ availability to the bird due to chelate formation leading to lowered feed consumption (Selle et al., 2009; Wilkinson et al., 2014). Hence, when feeding broiler chickens $\mathrm{P}$ deficient diets, a reduction in the dietary Ca content led to improved P digestibility, bone P and performance (Walk et al., 2012; Adeola and Walk, 2013). The increased broiler chickens performance could also be attributed to increased activity of endogenous phytase at lower Ca level. Similarly, Bradbury et al. (2014) observed that birds given a diet with Ca:non-Phytate $\mathrm{P}$ ratio of 4:1 had the lowest tibia ash and standing ability in comparison to lower ratios, resulting in impaired mobility.

The source of available $\mathrm{P}$ in the diets, regardless of whether the $\mathrm{P}$ was from an inorganic source or from the test feed ingredients, did not affect the bird performance. Similar findings were reported by Jang et al. (2003) where the source of available P did not affect feed intake or growth of broiler chickens fed either wild or low phytate barley and corn varieties. Thus, the most significant factor affecting the performance of chicks in the present study was the content of available P. Furthermore, feed efficiency was not affected by dietary available $\mathrm{P}$ content and thus nutrient utilization in broiler chicks is similar regardless of the available P content. Our findings agree with 
Thacker et al. (2013) and Jiang et al. (2013) where feed efficiency in broiler chicks was similar despite differences in the dietary available P content.

The CP digestibility was lower in the SBM-normbarley-based diets compared with pea based diets, which can be attributed to the higher barley content in the SBM-normbarley-based diets. Barley contains a higher content of non-starch polysaccharides which is known to increase digesta viscosity and reduce nutrient digestibility through their encapsulating effect (Hesselman and Aman, 1986; Campbell et al., 1989). Also, a reduction in CP digestibility due to increasing dietary barley content was observed in broiler chickens fed diets that contained corn, soybean, and wheat (Anderson et al., 2012). Neither pea variety nor inorganic P content influenced CP digestibility, which is consistent with the study of Thacker et al. (2013) showing comparable $\mathrm{CP}$ digestibility in broiler chicks fed either low phytate or normal phytate pea based diets.

The Lphybarley-Lphypea-based diets had a higher P retention compared with the SBM-normbarley- and normbarley-normpea-based diets. This response is in agreement with Jang et al. (2003) and Leytem et al. (2007) who compared several normal with low-phytate grain-based diets. The increased retention is likely a result of the reduced dietary phytate content which would cause a reduction in the formation of insoluble phytate-P complexes that affect P digestibility. Similarly, the P excretion was lowest for Lphybarley-Lphypea-based diets indicating high absorption of $\mathrm{P}$.

The increased P retention with decreasing P content in the Lphybarley-Lphypea based diets also reflects decreased $\mathrm{P}$ excretion during a deficiency in $\mathrm{P}$ supply. Similarly, Mutucumarana et al. (2014) found decreased P retention with increasing non-phytate $\mathrm{P}$ content in broiler chickens fed canola based diets. Reducing the iP content in the Lphypea-Lphybarley-based diets increased P retention. Viveros et al. (2002) reported that birds are able to increase $\mathrm{P}$ retentions with decreasing non-phytate P. This was due to increased phytate hydrolysis during P deficiency since the birds can increase intestinal phytase activity during times of P deficiency (Mutucumarana et al., 2015). However, the increased retention was not sufficient to meet the birds' requirement as depicted by the reduced tibia ash content and bone length. The bone ash content and length were used as indexes of bone mineralization because about $80 \%$ of the absorbed $\mathrm{P}$ is deposited in the bone. To maintain homeostasis during a P deficiency, the animal will mobilize skeletal reserves and this bone resorption leads to depressed bone growth and mineralization (Cuisinier-Gleizes et al., 1976). The diets with 50\% less inorganic $\mathrm{P}$ inclusion or no supplemental $\mathrm{P}$ resulted in reduced available $\mathrm{P}$ content that led to depressed tibia length and ash content. Our results are consistent with those of Viveros et al. (2002), Karimi et al. (2011) and Thacker et al. (2013) who reported decreased bone ash content and length in broiler chickens fed P-deficient diets.

It is clear that the efficiency of P utilization depends not only on the phytate and inorganic P content but also on the type of ingredients used as shown by a lack of change in $\mathrm{P}$ retention in the normbarley-normpea-based diets and a decrease in P retention in the SBM-normbarley-based diets. For example, Iyayi et al. (2013) reported increased $\mathrm{P}$ retention in broiler chickens fed an increasing content of peanut flour based diets and increasing non-phytate P content. In contrast, Liu et al. (2013) and Iyayi et al. (2013) found declining P retention as a result of increasing non-phytate P 
content, in broiler chickens fed soybean meal and pea nut flour based diets. Thacker et al. (2009) and Liu et al. (2014) observed no change in P retention with a reduction in $\mathrm{P}$ for broiler chicks fed barley or soybean meal-based diets.

For poultry diets based on ingredients with high phytate bound $\mathrm{P}$, the addition of inorganic P overcomes the negative effects of phytate on broiler performance. However, the excreted indigestible $\mathrm{P}$ from ingredients with a high phytate $\mathrm{P}$ is of environmental concern. It is evident that the $\mathrm{P}$ was lowest for the Lphybarley-Lphypea based diets, hence, less environmental pollution through manure is expected with usage of low phytate grains. In addition, the usage of low phyate grains allowed for a $29 \%$ reduction in the amount of inorganic P included in the broiler starter diets.

\section{References}

A de ola O., Walk C.L. (2013). Linking ileal digestible phosphorus and bone mineralization in broiler chickens fed diets supplemented with phytase and highly soluble calcium. Poultry Sci., 92: 2109-2117.

A nd ers on D.M., M a c I s a a c J.L., S a f a m e hr A. (2012). Dilution of broiler chicken diets with whole hulless barley. J. Appl. Poult. Res., 21: 399-406.

AOAC (1990). Official Methods of Analysis. 15th ed. Association of Analytical Chemistry, Washington, DC.

B erndt T., Thomas LF., Craig T.A., Sommer S., Li X., Bergstralh E.J., Kumar R. (2007). Evidence for a signaling axis by which intestinal phosphate rapidly modulates renal phosphate reabsorption. Proc. Natl. Acad. Sci. USA, 104: 11085-11090.

Bradbury E.J., Wilkins on S.J., Cronin G.M., Thomson P.C., B ed ford M.R., Cow i e s o n A.J. (2014). Nutritional geometry of calcium and phosphorus nutrition in broiler chicks. Growth performance, skeletal health and intake arrays. Animal, 8: 1071-1079.

C a m p b e 11 G.L., R o s s n a g e 1 B.G., C la s s e n H.L., Th a c k e r P.A. (1989). Genotypic and environmental differences in extract viscosity of barley and their relationship to its nutritive value for broiler chickens. Anim. Feed Sci. Technol., 26: 221-230.

CCAC (2009). Guide to the Care and Use of Experimental Animals. 2nd ed. Vol. 1. CCAC, Ottawa, Ontario, Canada.

Cuis inier-Gleizes P., Thomasset M., Sainteny-Debove F., Mathieu H. (1976). Phosphorus deficiency, parathyroid hormone and bone resorption in the growing rat. Calcif. Tiss. Res., 20: 235-249.

D i l g e r R.N., A d e o la O. (2006). Estimation of true phosphorus digestibility and endogenous phosphorus loss in growing chicks fed conventional and low-phytate soybean meals. Poultry Sci., 85: 661-668.

H e s s e $1 \mathrm{~m}$ a n K., A m a n P. (1986). The effect of $\beta$-glucanase on the utilization of starch and nitrogen by broiler chickens fed on barley of low- or high-viscosity. Anim. Feed Sci. Technol., 15: 83-93.

H u a g W., Lantz s c h H.J. (1983). Sensitive method for rapid determination of phytate in cereal and cereal products. J. Sci. Food Agric., 34: 1423-1427.

Iy a y i E.A., Fru-Nji F., A deola O. (2013). True phosphorus digestibility of black-eyed pea and peanut flour without or with phytase supplementation in broiler chickens. Poultry Sci., 92: 1595-1603.

J a n g D.A., F a d e 1 J.G., K 1 a s ing K.C., M i r e 1 e s A.J. Jr., Er n s t R.A., Yo ung K.A., C o o k A., R a b o y V. (2003). Evaluation of low-phytate corn and barley on broiler chick performance. Poultry Sci., 82: 1914-1924.

Ji ang X.R., Lu o F.H., Qu M.R., B on tempo V., Wu S.G., Zhang H.J., Yue H.Y., Qi G.H. (2013). Effects of non-phytate phosphorus levels and phytase sources on growth performance, serum biochemical and tibia parameters of broiler chickens. Ital. J. Anim. Sci.,12: 375-380.

K a h in d i R.K., T ha c k e r P.A., N y a c h o t i C.M. (2015). Nutrient digestibility in diets containing low-phytate barley, low-phytate field pea and normal-phytate field pea, and the effects of microbial 
phytase on energy and nutrient digestibility in the low and normal-phytate field pea fed to pigs. Anim. Feed Sci. Technol., 203: 79-87.

K ari mi A., B e d ford M.R., S a d e g h i G.H., G h o b a d i Z. (2011). Influence of dietary non-phytate phosphorous levels and phytase supplementation on the performance and bone characteristics of broilers. Rev. Bras. Cienc. Avic., 13: 43-51.

Leytem A.B., Thacker P.A., Turner B.L. (2007). Phosphorus characterization in feces from broiler chicks fed low-phytate barley diets. J. Sci. Food Agric., 87: 1495-1501.

L i u J.B., Chen D.W., A d e o la O. (2013). Phosphorus digestibility response of broiler chickens to dietary calcium-to-phosphorus ratios. Poultry Sci., 92: 1572-1578.

L i u J.B., C h e n D.W., A d e o l a O. (2014). Casein supplementation does not affect true phosphorus digestibility and endogenous phosphorus loss associated with soybean meal for broiler chickens determined by the regression method. Can. J. Anim. Sci., 94: 661-668.

L o m e r M.C.E., Th o m p s o n R.P.H., C o m m i s s o J., K e e n C.L., P o w e 11 J.J. (2000). Determination of titanium dioxide in foods using inductively coupled plasma optical emission spectrometry. Analyst, 125: 2339-2343.

Mutucumarana R.K., Ravindran V., Ravindran G., Cowies on A.J. (2014). Measurement of true ileal digestibility and total tract retention of phosphorus in corn and canola meal for broiler chickens. Poultry Sci., 93: 412-419.

Mutucumarana R.K., Ravindran V., Ravindran G., Cowi es on A.J. (2015). Measurement of true ileal phosphorus digestibility in maize and soybean meal for broiler chickens: comparison of two methodologies. Anim. Feed Sci. Technol., 206: 76-86.

NRC (1994). Nutrient Requirements of Poultry. 9th ed. National Academies Press, Washington, DC.

NRC (2012). Nutrient Requirements of Swine. 11th ed. National Academies Press, Washington, DC.

Penido M.G., Alon U.S. (2012). Phosphate homeostasis and its role in bone health. Pediatr. Nephrol., 27: 2039-2048.

R a vi ndra n V., B ry de n L.W., K or n e g a y E.T. (1995). Phytates: occurrence, bioavailability and implications in poultry nutrition. Poult. Avian Biol. Rev., 6: 125-143.

Sebastian S., Touchburn S.P., Chavez E.R., Lague P.C. (1997). Apparent digestibility of protein and amino acids in broiler chickens fed a corn-soybean diet. Poultry Sci., 76: 1760-1769.

S elle P.H., Cowies on A.J., R avindran V. (2009). Consequences of calcium interactions with phytate and phytase for poultry and pigs. Livest. Sci., 124: 126-141.

T h a c k e r P.A., H a q I., W i 11 in g B.P., L e y t e m A.B. (2009). The effects of phytase supplementation on performance and phosphorus excretion from broiler chickens fed low phosphorus-containing diets based on normal or low-phytic acid barley. Asian-Aust. J. Anim. Sci., 22: 404-409.

Th a c k e r P.A., D e e p A., P e tri D., Wa rk e n t in T. (2013). Nutritional evaluation of low-phytate peas (Pisum sativum L.) for young broiler chicks. Arch. Anim. Nutr., 67: 1-14.

Ve u m T.L (2010). Phosphorus and calcium nutrition and metabolism. In: Phosphorus and calcium utilization and requirements in farm animals, D.M.S.S. Vitti, E. Kebreab (eds). CAB International, Oxfordshire, UK, pp. 94-111.

Viveros A., Bren es A., A rij a I., C e n t e n o C. (2002). Effects of microbial phytase supplementation on mineral utilization and serum enzyme activities in broiler chicks fed different levels of phosphorus. Poultry Sci., 81: 1172-1183.

Walk C.L., A d d o-Chid i e E.K., B e dford M.R., A d e o la O. (2012). Evaluation of a highly soluble calcium source and phytase in the diets of broiler chickens. Poultry Sci., 91: 2255-2263.

Wilkinson S.J., B radbury E.J., B edford M.R., C ow i e s on A.J. (2014). Effect of dietary non-phytate phosphorus and calcium concentration on calcium appetite of broiler chicks. Poultry Sci., 93: 1695-1703.

W o y e n g o T.A., S 1 o m in s k i B.A., J o n e s R.O. (2010). Growth performance and nutrient utilization of broiler chickens fed diets supplemented with phytase alone or in combination with citric acid and multicarbohydrase. Poultry Sci., 89: 2221-2229.

Wo y e n g o T.A., N y a c h ot i C.M. (2013). Anti-nutritional effects of phytic acid in diets for pigs and poultry - current knowledge and directions for future research. Can. J. Anim. Sci., 93: 9-21. 